Article

\title{
Evidence of Photo-Thermal Effects on the First-Order Thermo-Induced Spin Transition of $\left[\left\{\mathrm{Fe}(\mathrm{NCSe})(\mathrm{py})_{2}\right\}_{2}(\mathrm{~m}-\mathrm{bpypz})\right]$ Spin-Crossover Material
}

\author{
Kamel Boukheddaden ${ }^{1}{ }^{*}$, Houcem Fourati ${ }^{1}$, Yogendra Singh ${ }^{1}$ and Guillaume Chastanet ${ }^{2} \mathbb{D}$ \\ 1 Groupe d'Etudes de la Matière Condensée, Université de Versailles, Université Paris-Saclay, CNRS UMR \\ 8635, 45 Avenue des Etats Unis, 78035 Versailles, France; houcemfourati@hotmail.fr (H.F.); \\ singhyogi813@gmail.com (Y.S.) \\ 2 Institut de Chimie de la Matière Condensée de Bordeaux, Université' de Bordeaux, \\ 87 Av. Doc. A. Schweitzer, F-33608 Pessac, France; guillaume.chastanet@icmcb.cnrs.fr \\ * Correspondence: kamel.boukheddaden@uvsq.fr
}

Received: 28 February 2019; Accepted: 22 March 2019; Published: 1 April 2019

\begin{abstract}
We have investigated by means of optical microscopy and magnetic measurements the first-order thermal spin transition of the $\left[\left\{\mathrm{Fe}(\mathrm{NCSe})(\mathrm{py})_{2}\right\}_{2}\right.$ (m-bpypz)] spin-crossover compound under various shining intensities, far from the light-induced spin-state trapping region. We found evidence of photo-heating effects on the thermally-induced hysteretic response of this spin-crossover material, thus causing the shift of the thermal hysteresis to lower temperature regions. The experimental results are discussed in terms of the apparent crystal temperature and are analyzed theoretically using two evolution equations of motion, written on the high-spin (HS) fraction and heat balance between the crystal and the thermal bath. A very good qualitative agreement was found between experiment and theory in the stationary regime, explaining the experimental observations well and identifying the key factors governing these photo-thermal effects.
\end{abstract}

Keywords: spin crossover; heat transfer; photo-magnetism; optical microscopy

\section{Introduction}

Switchable molecular solids [1,2] provide beautiful examples of first-order phase transitions. These materials [3-5] are recognized for their serious applications thanks to their reversible switching properties using temperature, pressure variations [6,7], light [8-16], magnetic $[17,18]$ and electric [19-21] fields, etc. It is important to notice that iron(II)-based spin-crossover (SCO) materials have been recognized as well adapted candidates for nano-structuration potentialities [22-26], allowing their integration into devices for various applications, such as display and memory devices [27-30], multimodal sensing [31-33], probes of contact pressure or shocks [7], as well as actuators [34-36].

The significant changes accompanying their physical properties, among which are the volume, color, elasticity, magnetism, dielectric susceptibility, and conductance [37], allow the detection of their switching by various physical techniques. As an example, the volume accompanying the spin transition was used to design microscopic actuators [38]. Furthermore, switchable thin films $[24,39,40]$ and nanoparticles [41-43] have also been synthesized and their properties analyzed. On the other hand, the spatiotemporal features at the macroscopic scale, accompanying the cooperative SCO materials exhibiting first-order transitions, remained quite unexplored until high-quality single crystals became available [44,45] and optical microscopy (OM) studies [46-52] were developed. As a result, the mechanism of the SCO transition on one single crystal was clarified, since it was identified that the transformation of a single crystal is governed by a nucleation and growth mechanism [51] in which the volume change at transition deploys long-range elastic interactions that delocalize the 
strain field at long distances. As a result, the electronic high-spin (HS) and low-spin (LS) phases, stabilized by the elastic strain, may coexist and compete as a function of temperature. In addition, $\mathrm{OM}$ investigations showed that although the first-order thermal transitions are sharp on one single crystal, the transition temperatures and so the thermal hysteresis loops are crystal-dependent and significantly depend on the crystal sizes and shapes [50]. Recent OM investigations [53] on the effect of light on the thermally-induced HS to LS transitions far from the Light-Induced Excited Spin-State Trapping (LIESST) effect [14] region, showed that under relatively strong light intensities the measured thermal hysteresis shifts to lower temperatures and the velocities of the HS-LS interfaces are also substantially affected. In the present work, we report on original photo-magnetic experiments conducted on a set of several single crystals of the $\left[\left\{\mathrm{Fe}(\mathrm{NCSe})(\mathrm{py})_{2}\right\}_{2}(\mathrm{~m}\right.$-bpypz) $]$ spin-crossover compound under various shining intensities. Compared to the OM measurements, the thermal hysteresis arising from magnetic measurements consists in an envelope of the various transitions of the SCO grains, and, consequently, the obtained response crucially depends on the size and shape distributions of the micro-crystals, ultimately leading to the smoothing of the thermal hysteresis profile. The present work thus aims at investigating the dependence of the thermal hysteresis on the shining light intensity.

It is worth mentioning that the first photo-thermal effects around the thermally-induced region, although not recognized as such, appeared for the first time in Reference [54], where the authors named it Light-Perturbed Thermal Hysteresis (LiPTH), which emerged from the study of the SCO material $\left[\mathrm{Fe}(\mathrm{phy})_{2}\right]\left(\mathrm{BF}_{4}\right)_{2}$ (phy = 1,10-phenanthroline-2-carbaldehyde phenylhydrazone) by Mössbuer spectroscopy under light irradiation in the temperature interval of 250-300 K. Moreover, it is important to mention that LIESST $[14,55]$ and Light-Induced Thermal Hysteresis (LITH) $[11,56]$, using continuous wave irradiations, are clearly very low-temperature phenomena $(<100 \mathrm{~K})$ arising from the competition between the quantum photo-excitation processes and thermal relaxation, which may induce in cooperative systems the emergence of new instabilities, as is explained in Reference [11]. Above this region, the lifetime is so fast that ultrafast pump-probe techniques are required to observe and analyze the photo-induced states [57,58]. The effect of continuous wave irradiation in this high-temperature region, i.e., around the SCO thermal hysteresis, is associated with another mechanism, which is discussed in the present work.

In this work, we demonstrate that a SCO compound under light intensity experiences photothermal effects that cause its photo-heating. The present experimental data are analyzed in terms of apparent temperature, resulting from thermal processes occurring in the sample, taking into account the photo-thermal heating and thermal exchanges between the sample and the thermal bath whose temperature is monitored. Indeed, as a consequence, the actual compound temperatures may sizably differ from the data displayed by the temperature controller, which is denoted as "apparent temperature". All the OM, photo-magnetic, and photo-thermal effects results are presented, discussed, and modeled using a microscopic description based on a non-equilibrium extension of the Ising-like model, combined with an equation of the heat balance between the SCO system and its environment (i.e., light and thermal bath) which gives the temporal dependence of the SCO compound's (or crystal's) temperature.

\section{Experiments and Results}

The investigations in this study were performed using optical microscopy and photo-magnetic measurements. Cryogenic optical microscopy investigations $[47,59,60]$ were conducted in a transmission mode using a standard optical microscope, Nikon Eclipse LV100, equipped with a fast CCD camera (DALSA Falcon 1.4 M100HG Color, 100 fps max, Dalsa, Ontario, Canada). Complete images of the crystal were recorded using an objective $\times 20$ (numerical aperture (NA) $=0.4$ with a resolution limit of $\sim 0.75 \mu \mathrm{m}$ ) as a function of temperature in transmission mode. The illumination was provided by a tungsten halogen lamp, whose intensity was controlled in order to study the consequence of the photo-heating effects on the spin transition. 
The experiments were performed on one single crystal of the compound $\left[\left\{\mathrm{Fe}(\mathrm{NCSe})(\mathrm{py})_{2}\right\}_{2}\right.$ (m-bpypz)], where py = pyridine and $\mathrm{m}$-bpypz $=3,5$-bis(2-pyridyl)-pyrazolate [61], whose molecular structure in the HS and LS states is displayed in Figure 1, in the course of the spin transition, where the HS and LS phases can be easily identified. The choice of this sample was due to the following three characteristics: (i) the strong thermo-chromic character of this complex at the transition, (ii) its sharp first-order transition, and (iii) its robustness at the transition which allows reversible thermal cycling studies with the same single crystal without the material degrading.

a) $200 \mathrm{~K}$ HS state

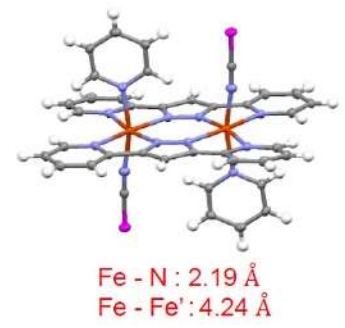

$90 \mathrm{~K}$ LS state

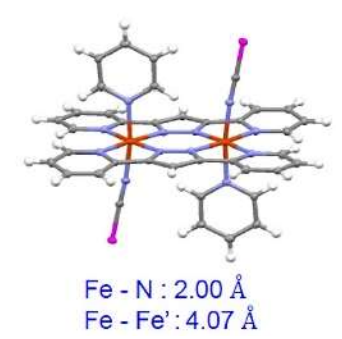

b)

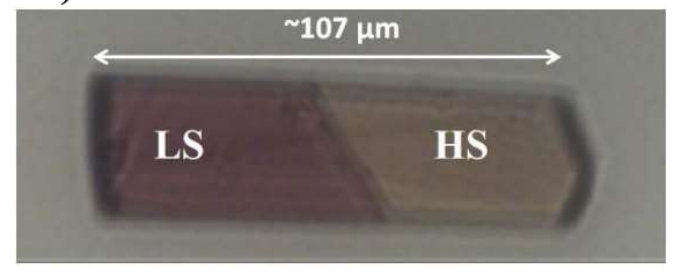

Figure 1. (a) Molecular structure of the $\left[\left\{\mathrm{Fe}(\mathrm{NCSe})(\mathrm{py})_{2}\right\}_{2}(\mathrm{~m}\right.$-bpypz)] molecule in the low-spin (LS) and high-spin (HS) states. The red and blue bonds are the most affected during the spin transition. The red dots represent Fe atoms, while the blue (gray) ones are $\mathrm{N}(\mathrm{C})$. The white and purple dots are hydrogen and Se atoms, respectively. The $\mathrm{Fe}-\mathrm{N}$ distance increases by about $10 \%$ at the transition. (b) Transmission image of the single crystal $\left[\left\{\mathrm{Fe}(\mathrm{NCSe})(\mathrm{py})_{2}\right\}_{2}(\mathrm{~m}-\mathrm{bpypz})\right]$ in the course of the spin transition on heating at $T=110.5 \mathrm{~K}$ and intensity $I=21 \mathrm{~mW} \mathrm{~cm}^{-2}$. The crystal size (length $\times$ width $\times$ thickness) is $\sim 107 \mu \mathrm{m} \times 29 \mu \mathrm{m} \times 10 \mu \mathrm{m}$.

\subsection{Photo-Magnetic Studies under Various Shining Intensities}

Magnetic susceptibility data were collected using a Quantum Design MPMS (Magnetic Property Measurement System) 5 SQUID (Superconducting QUantum Interference Device) magnetometer (Quantum Design, San Diego, CA, USA) under an applied field of $1 \mathrm{~T}$. The magnetic susceptibility $\left(\chi_{m}\right)$ of the title compound was measured over the 10 to $150 \mathrm{~K}$ temperature $(\mathrm{T})$ range with a temperature sweep rate of $1 \mathrm{~K} \mathrm{~min}^{-1}$ on a set of selected single crystals. Diamagnetic corrections for the sample holder and the material (using Pascal constants) were applied. The $\chi_{m} T$ versus $T$ plot is displayed in Figure 2. In the high-temperature region, the $\chi_{m} T$ value $\left(3.55 \mathrm{~cm}^{3} \mathrm{~K} \mathrm{~mol}^{-1}\right)$ is consistent with a HS ( $\mathrm{S}=2$ ) configuration of the hexacoordinated Fe(II) ions. Upon cooling and (respectively heating) in the dark, the $\chi_{m} T$ remains constant down to $111 \mathrm{~K}$ (respectively $114 \mathrm{~K}$ ), then sharply decreases (respectively increases) to ca. $0.25 \mathrm{~cm}^{3} \mathrm{~K} \mathrm{~min}^{-1}\left(3.45 \mathrm{~cm}^{3} \mathrm{~K} \mathrm{~min}-1\right.$ ), indicating the presence of an almost complete sharp HS to LS (respectively LS to HS) first-order spin transition with an equilibrium transition temperature, $T_{1 / 2} \simeq 113 \mathrm{~K}$.

Photo-magnetic measurements were performed with a set of photo-diodes coupled through an optical fiber to the cavity of a MPMS-55 Quantum Design SQUID magnetometer operating at $2 \mathrm{~T}$. The sample was first slowly cooled to $10 \mathrm{~K}$, until reaching the LS state, without any presence of residual HS fraction. The magnetic response of the sample under irradiation with white light excitation and a power (measured at the sample surface) of $\sim 5 \mathrm{~mW} \mathrm{~cm}^{-2}$ revealed a significant increase of the magnetic signal (see Figure 2) until the value $\chi_{m} T=1 \mathrm{~cm}^{3} \mathrm{~K} \mathrm{~mol}^{-1}$ at which the signal saturates, according to the LIESST process [14]. Then switching off the light and increasing the temperature led first to an increase of the magnetic signal until $T=50 \mathrm{~K}$, which indicated the presence of sizable zero field splitting effects and antiferromagnetic exchange between the two iron(II) centers of the binuclear [62-64]. Then, from this temperature, the HS fraction fell down around the relaxation temperature of $T($ LIESST) $=$ $60 \mathrm{~K}[56,65]$, given by the temperature at which the curve $\frac{\partial\left(\chi_{M} T\right)}{\partial T}$ vs. $T$ (given in the inset of Figure 2) reaches its minimum value. It is worth noting that excitations using $830 \mathrm{~nm}$ did not show any presence of a reverse-LIESST phenomenon on this compound. 


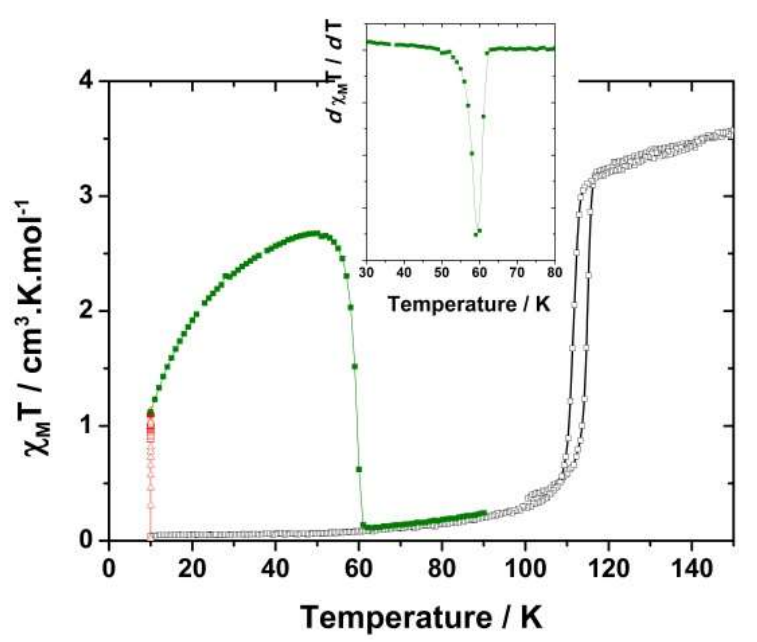

Figure 2. Thermal dependence of HS fraction (black circles) showing the occurrence of a first-order transition with a thermal hysteresis of $\sim 5 \mathrm{~K}$ wide. In the low-temperature region, the red triangles show the photo-excitation process at $10 \mathrm{~K}$ and the green squares denote the thermal dependence of the photo-induced metastable state in the dark. Inset is the derivative of the photo-magnetic signal in the region of $30-80 \mathrm{~K}$ to determine the relaxation temperature, $T($ LIESST) $=60 \mathrm{~K}$.

The effect of light on the thermal hysteresis of the present compound is presented in Figure 3a, where $\chi_{m} T$ is measured for several light intensities of an $830 \mathrm{~nm}$ excitation, at a temperature scan rate of $0.5 \mathrm{~K} \mathrm{~min}^{-1}$. At first sight, one can easily remark that the increase of the light intensity excitation results in the shift of the thermal hysteresis to low-temperature regions. This trend is expected for a light-induced heating effect. On the other hand, the plot of the upper and lower transition temperature as a function of the intensity of light (Figure 3b) show that the hysteresis width remains almost constant in this process.

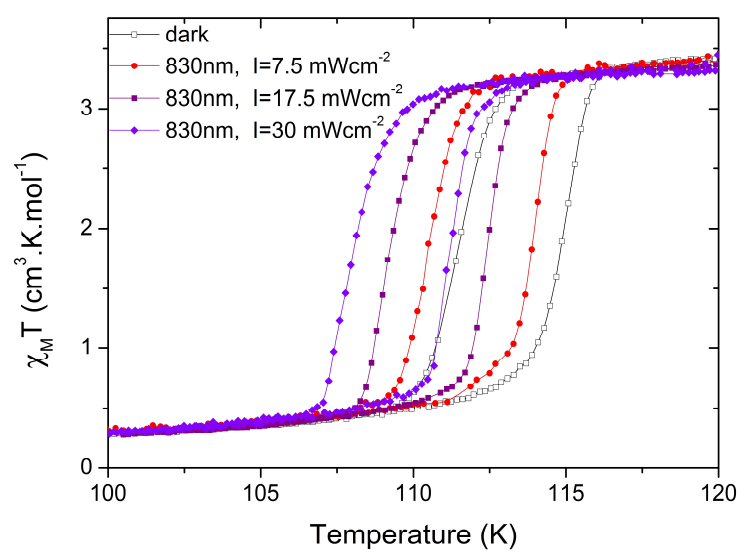

(a)

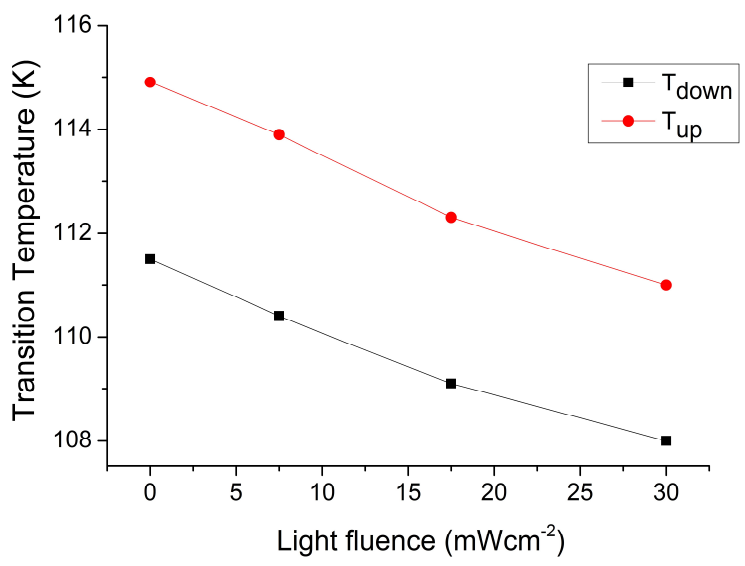

(b)

Figure 3. (a) Thermal dependence of the magnetic moment $\left(\chi_{m} T\right)$ under various light irradiation intensities, given in the figure, showing a significant shift of the thermal hysteresis to low-temperature regions. (b) Light intensity dependence of the upper and lower transition temperatures of the thermal hysteresis.

\subsection{Optical Microscopy Thermal Hysteresis and Photo-Heating Effects}

Figure $4 \mathrm{a}$ depicts some selected snapshots of the single crystal [\{Fe(NCSe)(py $\left.\left.)_{2}\right\}_{2}(\mathrm{~m}-\mathrm{bpypz})\right]$ transformation in the vicinity of the spin transition, recorded at a scan rate of $r=0.2 \mathrm{~K} \mathrm{~min}^{-1}$ with a relatively weak light intensity of the microscope, $I=21 \mathrm{~mW} \mathrm{~cm}^{-2}$. For both cooling and heating processes, the snapshots of Figure $4 \mathrm{a}$ indicate that the spin transition on one single crystal proceeds through a single domain nucleation and growth mechanism, with a well identified HS-LS interface which propagates along the crystal length. The origin of such a single domain nucleation is attributed 
here to long-range elastic interactions between the SCO molecules, arising from the large crystal volume change $(\sim 3 \%)$ at the transition [66-72]. Indeed, the local volume change at the transition on each site is felt by the other molecules at long-range distances, due to an image pressure (negative in the case of positive volume misfit and positive in the opposite case) $[73,74]$ traveling from the crystal boundary (the surface) in the form of an acoustic wave. As a result, the nucleation from the border of the crystal, which can be initiated randomly (a stochastic process) or by the existence of temperature gradients, generates long-range stresses, which prevent the nucleation from other sites, in the case of strong cooperative systems. The thermo-chromic transformation from the diamagnetic LS state to the paramagnetic HS state of the single crystal, illustrated in Figure 4a is consistent with the optical spectra, reported in Figure 4b, where we can clearly identify the absorption bands of the LS and HS states.
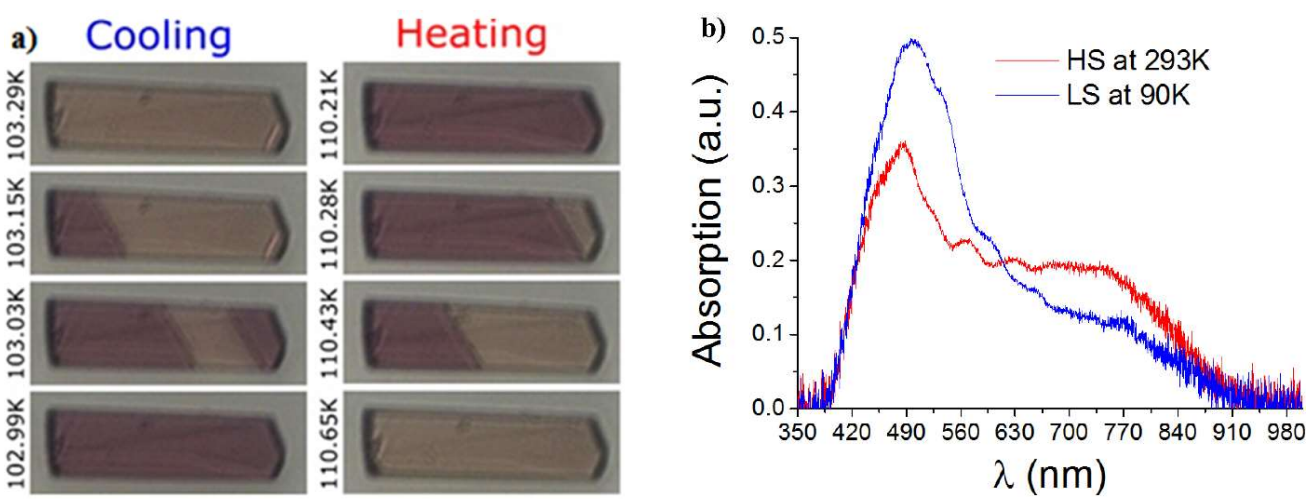

Figure 4. (a) Selected optical microscopy (OM) snapshots on cooling and heating showing the experimental spatiotemporal behavior of $\left[\left\{\mathrm{Fe}(\mathrm{NCSe})(\mathrm{py})_{2}\right\}_{2}\right.$ (m-bpypz)] single crystal along the spin transition, recorded at a scan rate of $r=0.2 \mathrm{~K} \mathrm{~min}^{-1}$ and light intensity of $I=21 \mathrm{~mW} \mathrm{~cm}^{-2}$. The dark (respectively light) phase corresponds to the LS (respectively HS) state. (b) Optical spectra of the current single crystal recorded in the LS (blue) and HS (red) states, showing absorption bands in the visible region.

Taking benefit from the thermo-chromic character of the present spin transition, we could derive quantitatively from the recorded images the average HS fraction, which is simply equal to the surface of the light areas appearing in the snapshots of Figure 4. On the other hand, to minimize the signal-noise ratio, one could also follow the optical density $\left(O D=\log _{10} \frac{I_{0}}{I}\right)$, where $I_{0}$ is the bright field intensity and $I$ is the transmitted intensity through the crystal. This OD scales with the HS fraction, $n_{H S}$, to which it connects through the relation, $n_{H S}=\frac{\left(O D-O D_{L S}\right)}{\left(O D_{H S}-O D_{L S}\right)}$, where $O D_{L S}$ (respectively $\left.O D_{H S}\right)$ is the optical density of the LS (respectively HS) state.

Figure 5 depicts the thermal hysteresis derived from the variation of the average optical density of the crystal obtained for various shining intensities at a constant temperature scan rate $(0.2 \mathrm{~K}$ $\min ^{-1}$ ). The chosen low value of the scan rate, $0.2 \mathrm{~K} \mathrm{~min}^{-1}$, excludes the presence of any sizable kinetic effects on the thermal hysteresis. The HS fraction is plotted here as a function of the apparent temperature (which is the temperature indicated by the controller and which probably differs from that of the crystal).

As mentioned above, the thermal dependence of the HS fraction, derived from the evolution of the average optical density of the single crystal, presented in Figure 5, shows a global and monotonous shift of the thermal hysteresis to lower temperature regions, as clearly confirmed by the decrease of the cooling and heating transition temperatures of the thermal hysteresis. This behavior is attributed to the photo-heating effects produced by light absorption, which obviously favors the HS state. It is worth noting that this behavior is different from that arising from the temperature scan rate kinetics which affect equally both branches of the thermal hysteresis and keeps the middle of the thermal hysteresis invariant [53,75-77]. 


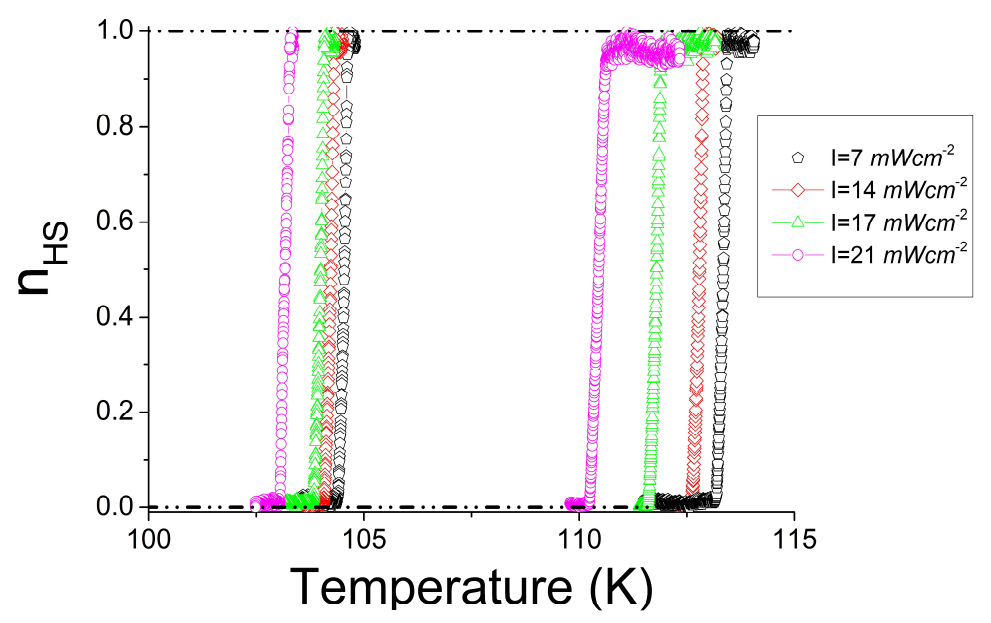

Figure 5. Set of thermal hystereses recorded at various shining intensities, with the temperature scan rate of $0.2 \mathrm{~K} \mathrm{~min}^{-1}$ showing the shift of the thermal hysteresis to lower temperature regions as a result of photo-heating effects.

In the present situation where the crystal is maintained under light, its temperature, $T$, is higher than that of the thermal bath, $T_{B}$, indicated by the temperature controller, which now becomes an apparent temperature. Furthermore, all transition temperatures are in the range of 102-113 K, excluding molecular photo-induced processes, such as LIESST [14,55] and LITH [11,15,45,56,78,79] effects, which are significant in this system only below $60 \mathrm{~K}$.

On the other hand, the analysis of the light intensity dependence of the upper and lower transition temperatures (denoted $T^{+}$and $T^{-}$) of the thermal hysteresis of Figure 5, leads to a linear plot, reported in Figure 6, with almost the same slopes for the two sets of data. This tendency suggests that the photo-thermal effects are proportional to the intensity of light, an idea that will be incorporated in the theoretical section. Finally, the results of the optical microscopy, reported in Figure 6, agree well with the photo-magnetic data (Figure 3), despite a slight difference in the switching temperatures as often observed between two different characterization techniques.

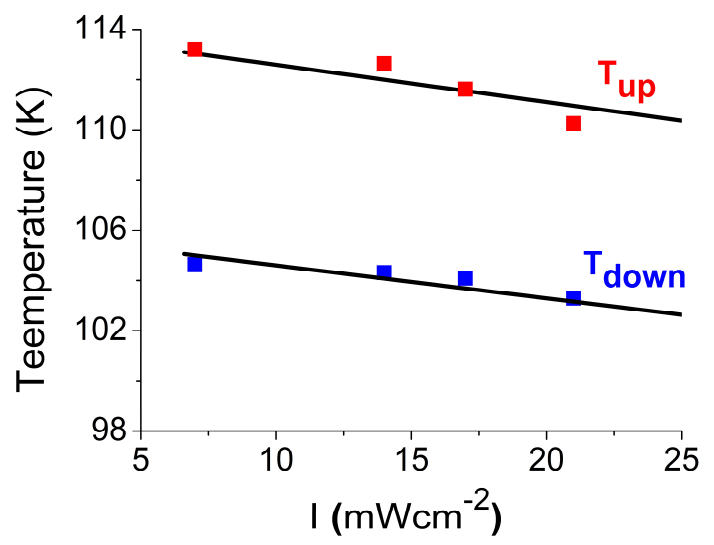

Figure 6. The dependence of the apparent switching temperatures upon the shining intensity, derived from Figure 5. The specific shining intensities were measured at the location of the sample cell.

\section{Theory of the Photo-Heating Effects}

The theoretical description of the photo-heating effects requires the use of non-equilibrium thermodynamics to establish the equations of motion of the HS fraction and crystal temperature. It is important here to consider that the crystal is in contact with a thermal bath whose temperature, $T_{B}$, is monitored at a temperature sweep rate. The crystal is maintained under light intensity that causes its photo-heating $[48,53,75,80]$, with a constant rate. The photo-heating effect is assumed to be 
proportional to the light intensity, the optical absorption of the SCO material and must also depend on the crystal heat capacity $[35,81]$.

\subsection{The Thermally-Induced Spin Transition}

The spin transition system is simply described here by an Ising-like model, whose thermodynamic aspects have already been discussed in several papers [50,82-84]. In this model, each SCO molecule is represented by two levels of fictitious spin, $S$, whose eigenvalues +1 and -1 are respectively associated with the HS and LS state of the molecule. The Hamiltonian system writes

$$
H=-J \sum_{i} s_{i} s_{j}+\Delta_{\text {eff }} \sum_{i} s_{i}
$$

where $J>0$ describes the ferroelastic interaction among the spin-crossover units and $\Delta_{\text {eff }}=$ $\left(\Delta-k_{B} T \ln g\right)$ is the effective energy gap, which includes the contributions of the ligand field energy, $\Delta$, which stabilizes the LS state and the degeneracies ratio, $g=g_{\mathrm{HS}} / g_{\mathrm{LS}}$, between the LS and HS states, which favors the HS state at high temperature. The latter, plays the role of an entropic term which competes with the ligand field. The mean-field analysis of Hamiltonian, Equation (1), follows very standard developments which lead quite easily to the following homogenous, free energy:

$$
F_{h o m}=\frac{1}{2} J m^{2}-k_{B} T \ln \left[\left(2 g \cosh \frac{J m-\Delta_{e f f}}{k_{B} T}\right)\right]
$$

where $m=\langle s\rangle$ is the average fictitious magnetization per site. From the analytical expression of the free energy, given in Equation (2), one can straightforwardly derive the self-consistent equation, after minimizing the variational free energy in Equation (2) with respect to the net "magnetization", $m$, through the relation of $\frac{\partial F_{h o m}}{\partial m}=0$. This leads to the state equation

$$
m=\tanh \beta\left[J m-\Delta_{e f f}\right]
$$

where $\beta=\frac{1}{k_{B} T}$ and whose resolution gives the temperature dependence of the HS fraction, $n_{H S}$, that is the fraction of molecules occupying the HS state, which simply connects to the average fictitious magnetization as

$$
n_{H S}=\frac{1+m}{2}
$$

A brief look at Equation (3) shows that $m=0$ is always a solution when $\Delta_{\text {eff }}=\Delta-k_{B} T \ln g=0$. Once $m=0$, it follows that $n_{H S}=\frac{1}{2}$; this means that the temperature cancelling the effective field is the transition temperature of the system, the expression of which writes simply as $T_{e q}=\frac{\Delta}{k_{B} \ln g}$.

It is interesting to note that the resolution of Equation (3) does not need any numerical simulations to be performed; despite the self-consistent nature of this equation, it can be easily reversed by expressing the temperature as a function of the magnetization:

$$
T=\frac{2(J m-\Delta)}{k_{B} \ln \left[\left(\frac{1+m}{1-m}\right) \frac{1}{g}\right]}
$$

Then changing $m$ from -1 to +1 by accounting for the limits gives, in a unique way, the associated temperature, $T$. An example of the thermal dependence of the HS fraction in the case of the first-order transition is given in Figure 7, where the stable, metastable, and unstable states are clearly highlighted. 


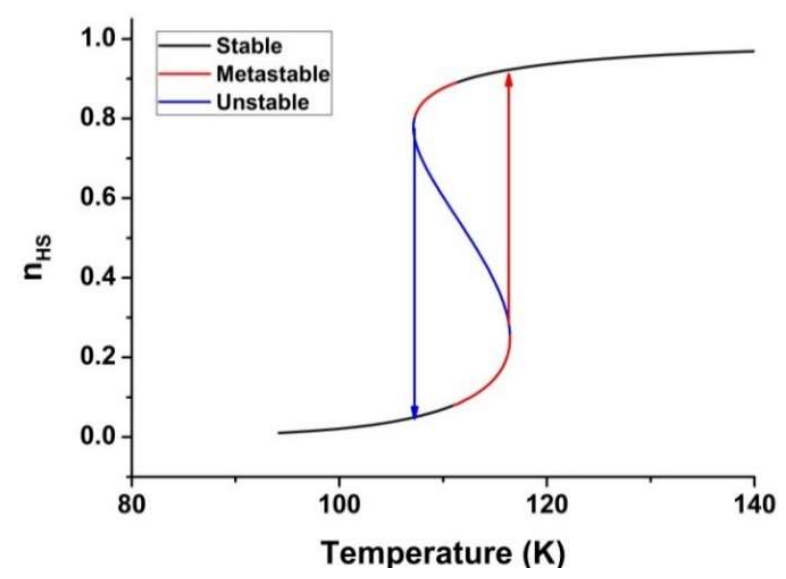

Figure 7. Thermal dependence of the HS fraction showing a hysteresis loop with respective upper and lower transition temperatures, 116 and $106 \mathrm{~K}$. Stable, metastable, and unstable regions are plotted with black, red, and blue lines, respectively. The parameters values are: $\Delta=394 \mathrm{~K}, g=1097$, and $J=155 \mathrm{~K}$.

\subsection{Light-Induced Photo-Heating Effect}

A brief trip into the non-equilibrium statistical mechanics world is necessary to well describe the photo-heating effects under study. The time-dependence of the "magnetization" or the HS fraction can be deduced from the mean-field free energy landscape, given in Equation (2), through the general motion equation, $\frac{\partial m}{\partial t}=-\Gamma \frac{\partial F}{\partial m}$, where the free energy plays the role of the driving force of the HS changes. Interestingly, this expression finds the equilibrium properties of the system, since in the stationary state, where $\frac{\partial m}{\partial t}=0$ is fulfilled, one recovers the equation of state (Equation (3)).

On the other hand, photo-heating generates another equation of motion on temperature, which should account for the crystal heating due to light and for the thermal exchanges between the crystal and its immediate environment-here, the thermal bath. Here, we stay in the homogenous mean-field, and so we neglect the spatiotemporal effects on temperature and HS fraction, as well as the thermal diffusion inside the material. Furthermore, the weak light power used in the experimental studies presented above, do not produce any photo-induced effects, like LIESST and LITH, which are omitted in these theoretical developments.

Within these elements, the equations of motion of HS fraction and temperature are:

$$
\begin{gathered}
\left\{\frac{\partial m}{\partial t}=-\Gamma\left(m-\tanh \beta\left(J m-\Delta_{e f f}\right)\right)\right. \\
\left\{\frac{\partial T}{\partial t}=-\frac{1}{\tau}\left(T-T_{B}\right)+\frac{I_{0} \sigma}{C_{p}(T, m)}\right.
\end{gathered}
$$

In Equation (6), $\Gamma$ fixes the time scale of the relaxation of the HS fraction. Equation (7) sets the temporal evolution of the SCO material's temperature, $T$. The first right-hand term describes the heat exchanges between the SCO system and the thermal bath, $T_{B}$, with a time scale of $\frac{1}{\tau}$, while the second takes into account the temperature increase due to the photo-heating effects under the light intensity, $I_{0}$, where $\sigma$ is the optical absorption and $C_{p}$ is the system's heat capacity which depends on the temperature and "magnetization" or HS fraction.

It is worth noting here that, in the experiment, $T_{B}$ is the measured temperature by the temperature probe and then consists in an apparent temperature, while the true $\mathrm{SCO}$ crystal/powder temperature remains unknown. Here, we are mainly interested in the stationary state for which $\frac{\partial m}{\partial t}=0$ and $\frac{\partial T}{\partial t}=0$, leading to the new state equations,

$$
\left\{m=\tanh \beta\left(J m-\Delta+\frac{k_{B} T}{2} \ln g\right)\right.
$$




$$
\left\{T=T_{B}+\frac{\alpha}{C_{p}(T, m)}\right.
$$

with $\alpha=\sigma I_{0} \tau$ and $C_{p}(T, m)=C_{p}^{L S}+\Delta C_{p}\left(\frac{1+m}{2}\right)$, where $\Delta C_{p}$ is the heat capacity change between the LS and HS phases. One can see that for $I_{0}=0$ (i.e., $\alpha=0$ ), there is no photo-heating, and the crystal instantaneously follows the bath temperature.

Combining Equations (8) and (9), we arrive at the following equation of state:

$$
T_{B}=\frac{(J m-\Delta)-\frac{\alpha X(m)}{C_{p}^{L S}+\Delta C_{p}\left(\frac{1+m}{2}\right)}}{X(m)}
$$

where,

$$
X(m)=\frac{1}{2} \ln \left[\left(\frac{1+m}{1-m}\right) \frac{1}{g}\right]
$$

The HS fraction vs. $T_{B}$ is determined from Equation (10) with heat capacity values, $C_{p}^{L S}=0.1$ a.u., and $C_{p}^{H S}=0.01$ a.u, given in arbitrary units and $J=155 \mathrm{~K}, \Delta=394 \mathrm{~K}, g=1097$.

The obtained results are summarized in Figure 8, which presents the apparent temperature, $T_{B}$, and the dependence of the HS fraction for various shining light intensities. We can clearly see that the model reproduces the experimental results quite well since the thermal hysteresis shifts downwards under strong shining intensities. However, we clearly see that the model exaggerates the shift in the lower branch of the thermal hysteresis due to the difference of heat capacities between the LS and the HS states.

a)

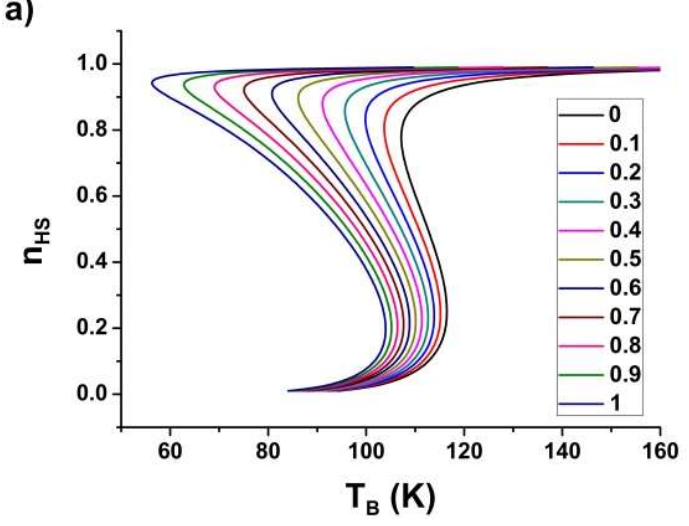

b)

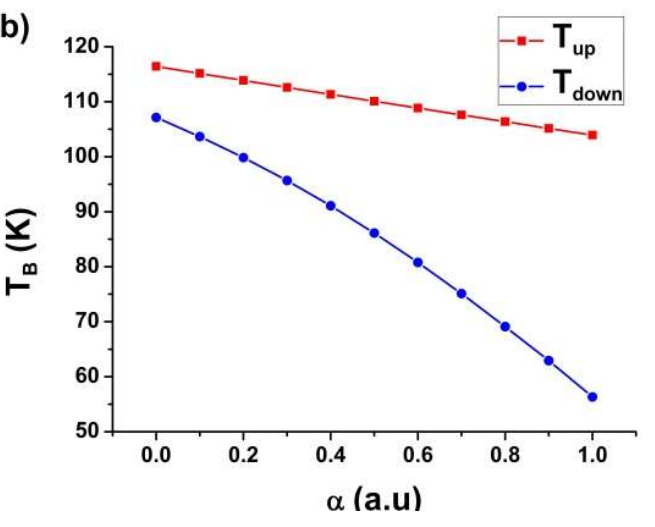

Figure 8. (a) Simulated bath-temperature $\left(T_{B}\right)$ dependence of the HS fraction under light causing its photo-heating for various light intensity values, given in arbitrary units. (b) Light intensity dependence of the upper and lower transition temperatures of the thermal hysteresis. Parameter values are: $J=155 \mathrm{~K}, \Delta=394 \mathrm{~K}, g=1097, C_{p}^{L S}=0.1$ a.u., and $C_{p}^{H S}=0.01$ a.u. (arbitrary units).

Figure 9a reports the bath-temperature dependence of the HS fraction for the same intensity values with a negligible heat capacity difference between the LS and HS states, i.e., $\Delta C_{p}=0$, while $C_{p}^{L S}=C_{p}^{H S}$ are different from zero. The results show the previous dissymmetry observed in the shift of the upper and lower switching temperature disappears, leading to a linear decrease of the transition temperatures as a function of the light intensity (Figure 9b), in very good qualitative agreement with the above magnetic and optical microscopy experimental results.

\subsection{Effect of Light Absorption}

It is interesting to note that this model accounts for the effects of the absorption of light along the sample thickness. At this end, the sample is now considered as a multilayer system with thickness, $\mathrm{L}$. Each layer has a coordinate, $x$, which corresponds to its depth relative to the top layer which has the coordinate $x=0$. Each layer then receives an intensity, $I(x)$, whose expression is 


$$
I(x)=I_{0} e^{-\frac{x}{\delta}}
$$

where, $\delta$ is a characteristic depth. Each thin layer then has its own equation of state:

$$
T_{B}(x)=\frac{(J m-\Delta)-\frac{\sigma \tau I_{0} e^{-\frac{x}{\delta}} X(m)}{C_{p}^{L S}+\Delta C_{p}\left(\frac{1+m}{2}\right)}}{X(m)}
$$

where, $X(m)$ is given in Equation (11). Equation (13) is then resolved for each $x$ value leading to $n_{H S}\left(T_{B}, I_{0}, x\right)$. The average HS fraction for a fixed intensity, $I_{0}$, is then obtained after the following averaging equation:

$$
\left\langle n_{H S}\right\rangle=\frac{1}{L} \int_{0}^{L} n_{H S}\left(x, T_{B}, I_{0}\right) d x
$$

This procedure is repeated for several values of the incident light intensity, $I_{0}$, which leads to the results of Figure 10.

a)

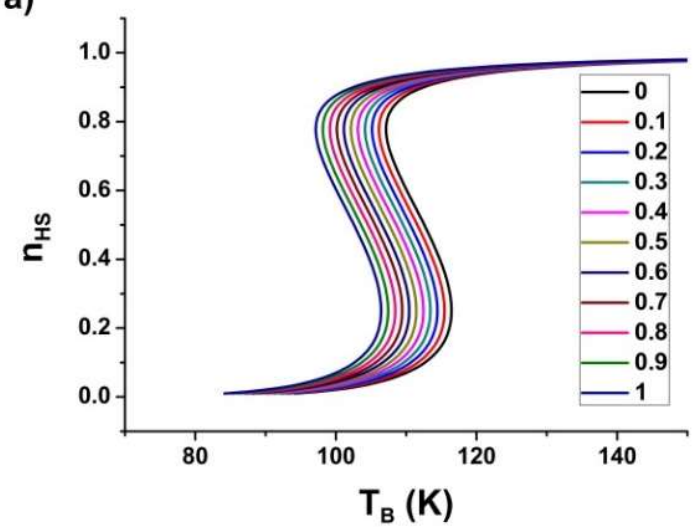

b)

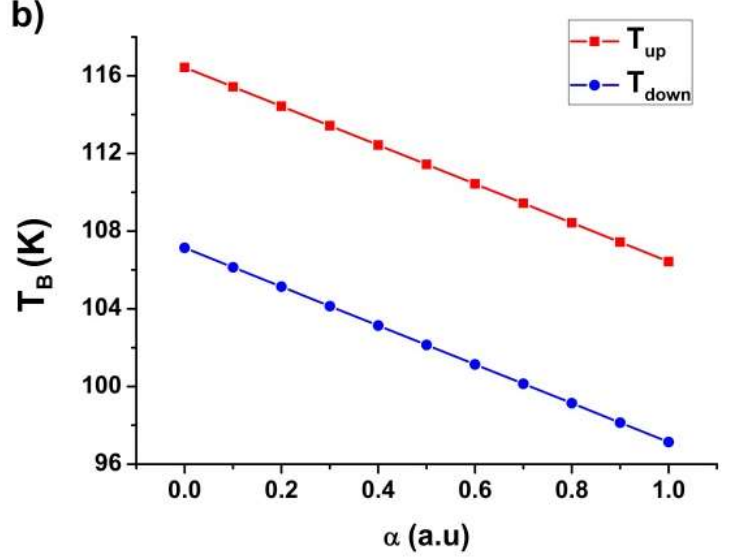

Figure 9. (a) Simulated bath-temperature $\left(T_{B}\right)$ dependence of the HS fraction under various light intensities (from 0 to 1 , given in arbitrary units) for, $\Delta C_{p}=0$, showing a monotonous linear shift of the hysteresis loop. (b) Light intensity dependence of the upper and the lower transition temperatures of the thermal hysteresis leading to parallel lines. Used parameter values are: $J=155 \mathrm{~K}, \Delta=394 \mathrm{~K}$, $g=1097, C_{p}^{L S}=0.1$ a.u., and $C_{p}^{H S}=0.1$ a.u.

a)

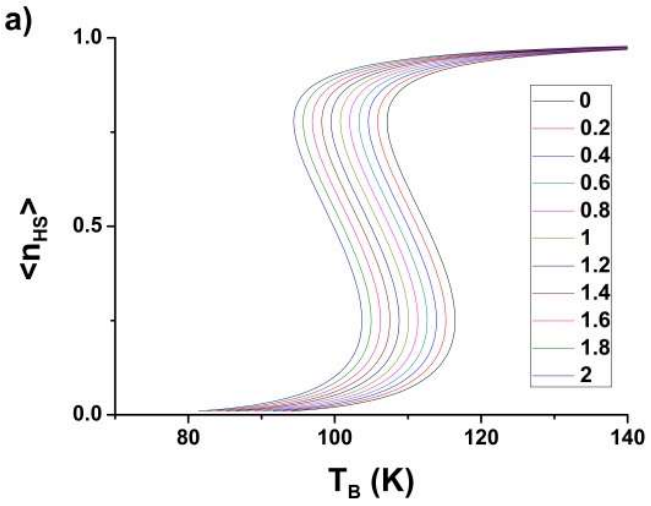

b)

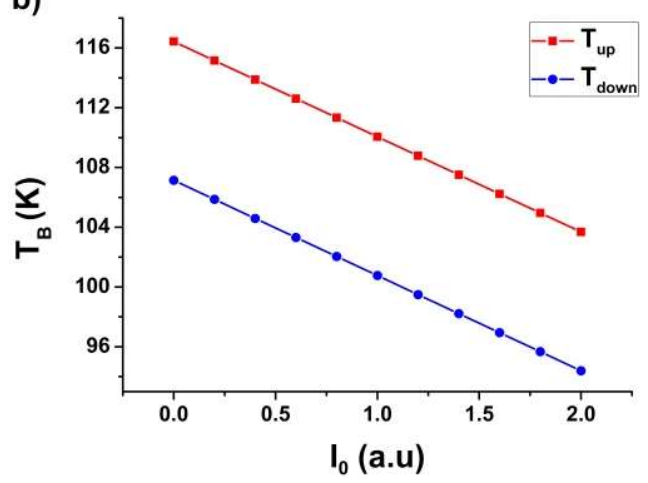

Figure 10. (a) Simulated bath-temperature $\left(T_{B}\right)$ dependence of the HS fraction under various light intensities (given in arbitrary units) including the effect of light absorption. (b) Light intensity dependence of the upper and lower transition temperatures of the thermal hysteresis. Used parameter values are: $J=155 \mathrm{~K}, \Delta=394 \mathrm{~K}, g=1097, C_{p}^{L S}=0.1$ a.u. (arbitrary unit), and $C_{p}^{H S}=0.1$ a.u., $\delta=1$ a.u., $L=1$ a.u. 


\section{Conclusions}

The effect of light excitation on the thermal hysteresis of a spin-crossover material have been investigated by means of photo-magnetic measurements on a set of single crystals as well as by optical microscopy on a unique single crystal. Both experiments lead to the same response of the thermal hysteresis which shifts to a lower temperature region as the intensity of the incident light is increased. This behavior is explained in terms of photo-heating effects due to the light absorption by the crystal and modeled by a microscopic model accounting for the light absorption and the thermal exchange between the crystal and the thermal bath. It is then deduced that the experimentally measured temperature is an apparent one, while that of the crystal differs notably as far as the light excitation intensity is increased. A very good agreement was found between the experimental data and the modeling.

Author Contributions: K.B. wrote down the model and supervised the work, H.F. performed the experimental optical microscopy measurements and the data treatment, Y.S. helped in the numerical simulations and the figures, and G.C. did the photo-magnetic measurements and the data analysis. All authors have contributed to the manuscript.

Funding: This research received no external funding.

Acknowledgments: The authors acknowledge the Université de Versailles, Université Paris-Saclay, Université de Bordeaux, CNRS (Centre national de la recherche scientifique), and the Laboratoire International Associé (LIA) IM-LED ("Impacting materials with light and electric fields and watching real time dynamics") for their financial support.

Conflicts of Interest: The authors declare no conflict of interest.

\section{Abbreviations}

$\begin{array}{ll}\text { SCO } & \text { Spin Crossover } \\ \text { HS } & \text { High-Spin } \\ \text { LS } & \text { Low-Spin } \\ \text { LIESST } & \text { Light-Induced Excited Spin-State Trapping } \\ \text { LITH } & \text { Light-Induced Thermal Hysteresis } \\ \text { OM } & \text { Optical Microscopy }\end{array}$

\section{References}

1. Gütlich, P.; Hauser, A. Thermal and light-induced spin crossover in iron(II) complexes. Coord. Chem. Rev. 1990, 97, 1-22. [CrossRef]

2. Sorai, M.; Seki, S. Magnetic Heat Capacity Due to Cooperative Low-Spin 1A $1 \rightleftharpoons$ High-Spin 5 T2 Transition in Fe(phen $)_{2}$ (NCS) ${ }_{2}$ Crystal. J. Phys. Soc. Japan 1972, 33, 575. [CrossRef]

3. Halcrow, M.A. Spin-Crossover Materials: Properties and Applications; John Wiley \& Sons Ltd.: Hoboken, NJ, USA, 2013.

4. Quintero, C.M.; Felix, G.; Suleimanov, I.; Sanchez Costa, J.; Molnar, G.; Salmon, L.; Nicolazzi, W.; Bousseksou, A. Hybrid spin-crossover nanostructures. Beilstein J. Nanotechnol. 2014, 5, 2230-2239. [CrossRef]

5. Peng, H.; Tricard, S.; Felix, G.; Molnar, G.; Nicolazzi, W.; Salmon, L.; Bousseksou, A. Re-Appearance of Cooperativity in Ultra-Small Spin-Crossover $[\mathrm{Fe}(\mathrm{pz})\{\mathrm{Ni}(\mathrm{CN})\}]$ Nanoparticles. Angew. Chem. Int. Ed. Engl. 2014. [CrossRef]

6. Jureschi, C.M.; Linares, J.; Rotaru, A.; Ritti, M.H.; Parlier, M.; Dîrtu, M.M.; Wolff, M.; Garcia, Y. Pressure sensor via optical detection based on a 1D spin transition coordination polymer. Sensors 2015, 15, 2388-2398. [CrossRef]

7. Boukheddaden, K.; Ritti, M.H.; Bouchez, G.; Sy, M.; Dîrtu, M.M.; Parlier, M.; Linares, J.; Garcia, Y. Quantitative Contact Pressure Sensor Based on Spin Crossover Mechanism for Civil Security Applications. J. Phys. Chem. C 2018, 122, 7597-7604. [CrossRef]

8. Decurtins, S.; Gütlich, P.; Hasselbach, K.M.; Hauser, A.; Spiering, H. Light-induced excited-spin-state trapping in iron(II) spin-crossover systems. Optical spectroscopic and magnetic susceptibility study. Inorgan. Chem. 1985, 24, 2174-2178. [CrossRef] 
9. Hauser, A. Reversibility of light-induced excited spin state trapping in the $\mathrm{Fe}(\mathrm{ptz})_{6}(\mathrm{BF} 4)_{2}$, and the $\mathrm{Zn}_{1-\mathrm{x}} \mathrm{Fe}_{\mathrm{x}}$ $(\mathrm{ptz})_{6}(\mathrm{BF} 4)_{2}$ spin-crossover systems. Chem. Phys. Lett. 1986, 124, 543-548. [CrossRef]

10. Hauser, A.; Adler, J.; Gütlich, P. Light-induced excited spin state trapping (LIESST) in [Fe(2-mephen) $]_{3}^{2+}$ embedded in polymer matrices. Chem. Phys. Lett. 1988, 152, 468-472. [CrossRef]

11. Desaix, A.; Roubeau, O.; Jeftic, J.; Haasnoot, J.G.; Boukheddaden, K.; Codjovi, E.; Linarès, J.; Noguès, M.; Varret, F. Light-induced bistability in spin transition solids leading to thermal and optical hysteresis. Eur. Phys. J. B 1998, 6, 183-193. [CrossRef]

12. Gütlich, P.; Garcia, Y.; Goodwin, H.A. Spin crossover phenomena in Fe(ii) complexes. Chem. Soc. Rev. 2000, 29, 419-427. [CrossRef]

13. Varret, F.; Boukheddaden, K.; Codjovi, E.; Enachescu, C.; Linarès, J. On the Competition Between Relaxation and Photoexcitations in Spin Crossover Solids under Continuous Irradiation. In Spin Crossover in Transition Metal Compounds II; Springer: Berlin/Heidelberg, Germany, 2004; Volume 234, pp. 199-229.

14. Hauser, A. Light-Induced Spin Crossover and the High-Spin $\rightarrow$ Low-Spin Relaxation. In Spin Crossover in Transition Metal Compounds; Chem, T.C., Ed.; Springer: New York, NY, USA, 2004; Volume 234, pp. 155-198.

15. Varret, F.; Boukheddaden, K.; Codjovi, E.; Maurin, I.; Tokoro, H.; Ohkoshi, S.; Hashimoto, K. Light-induced thermal hysteresis and intensity thresholds in molecular switcheable solids, by mean-field macroscopic master equation approach: Discussion of the experimental data obtained for Co-Fe Prussian Blue Analogues. Polyhedron 2005, 24, 2857-2863. [CrossRef]

16. Boukheddaden, K.; Sy, M. Direct Optical Microscopy Observation of Photo-Induced Effects and Thermal Relaxation in a Spin Crossover Single Crystal. Curr. Inorg. Chem. 2016, 6, 40-48. [CrossRef]

17. Bousseksou, A.; Negre, N.; Goiran, M.; Salmon, L.; Tuchagues, J.P.; Boillot, M.L.; Boukheddaden, K.; Varret, F. Dynamic triggering of a spin-transition by a pulsed magnetic field. Eur. Phys. J. B 2000, 13, 451-456.

18. Ould Moussa, N.; Ostrovskii, D.; Garcia, V.M.; Molnár, G.; Tanaka, K.; Gaspar, A.B.; Real, J.A.; Bousseksou, A. Bidirectional photo-switching of the spin state of iron(II) ions in a triazol based spin crossover complex within the thermal hysteresis loop. Chem. Phys. Lett. 2009, 477, 156-159. [CrossRef]

19. Mahfoud, T.; Molnar, G.; Bonhommeau, S.; Cobo, S.; Salmon, L.; Demont, P.; Tokoro, H.; Ohkoshi, S.; Boukheddaden, K.; Bousseksou, A. Electric-field-induced charge-transfer phase transition: A promising approach toward electrically switchable devices. J. Am. Chem. Soc. 2009, 131, 15049-15054. [CrossRef]

20. Rotaru, A.; Dugay, J.; Tan, R.P.; Guralskiy, I.A.; Salmon, L.; Demont, P.; Carrey, J.; Molnar, G.; Respaud, M.; Bousseksou, A. Nano-electromanipulation of spin crossover nanorods: Towards switchable nanoelectronic devices. Adv. Mater. 2013, 25, 1745-1749. [CrossRef]

21. Prins, F.; Monrabal-Capilla, M.; Osorio, E.A.; Coronado, E.; van der Zant, H.S. Room-temperature electrical addressing of a bistable spin-crossover molecular system. Adv. Mater. 2011, 23, 1545-1549. [CrossRef]

22. Cavallini, M. Status and perspectives in thin films and patterning of spin crossover compounds. Phys. Chem. Chem. Phys. 2012, 14, 11867-11876. [CrossRef] [PubMed]

23. Shepherd, H.J.; Molnár, G.; Nicolazzi, W.; Salmon, L.; Bousseksou, A. Spin Crossover at the Nanometre Scale. Eur. J. Inorg. Chem. 2013, 2013, 653-661. [CrossRef]

24. Cavallini, M.; Bergenti, I.; Milita, S.; Kengne, J.C.; Gentili, D.; Ruani, G.; Salitros, I.; Meded, V.; Ruben, M. Thin deposits and patterning of room-temperature-switchable one-dimensional spin-crossover compounds. Langmuir 2011, 27, 4076-4081. [CrossRef]

25. Naik, A.D.; Stappers, L.; Snauwaert, J.; Fransaer, J.; Garcia, Y. A biomembrane stencil for crystal growth and soft lithography of a thermochromic molecular sensor. Small 2010, 6, 2842-2846. [CrossRef] [PubMed]

26. Basak, S.; Hui, P.; Chandrasekar, R. Flexible and Optically Transparent Polymer Embedded Nano/Micro Scale Spin Crossover Fe(II) Complex Patterns/Arrays. Chem. Mater. 2013, 25, 3408-3413. [CrossRef]

27. Gütlich, P.G. Spin Crossover in Transition Metal Compounds I-III, 1st ed.; Springer: Berlin/Heidelberg, Germany, 2004.

28. Linares, J.; Codjovi, E.; Garcia, Y. Pressure and Temperature Spin Crossover Sensors with Optical Detection. Sensors 2012, 12, 4479-4492. [CrossRef] [PubMed]

29. Bousseksou, A.; Molnar, G.; Salmon, L.; Nicolazzi, W. Molecular spin crossover phenomenon: Recent achievements and prospects. Chem. Soc. Rev. 2011, 40, 3313-3335. [CrossRef]

30. Gütlich, P.; Gaspar, A.B.; Garcia, Y. Spin state switching in iron coordination compounds. Beilstein J. Organ. Chem. 2013, 9, 342-391. [CrossRef] [PubMed] 
31. Cavallini, M.; Melucci, M. Organic Materials for Time-Temperature Integrator Devices. ACS Appl. Mater. Interfaces 2015, 7, 16897-16906. [CrossRef] [PubMed]

32. Gentili, D.; Demitri, N.; Schäfer, B.; Liscio, F.; Bergenti, I.; Ruani, G.; Ruben, M.; Cavallini, M. Multi-modal sensing in spin crossover compounds. J. Mater. Chem. C 2015, 3, 7836-7844. [CrossRef]

33. Naik, A.D.; Robeyns, K.; Meunier, C.F.; Léonard, A.F.; Rotaru, A.; Tinant, B.; Filinchuk, Y.; Su, B.L.; Garcia, Y. Selective and Reusable Iron(II)-Based Molecular Sensor for the Vapor-Phase Detection of Alcohols. Inorg. Chem. 2014, 53, 1263-1265. [CrossRef]

34. Shepherd, H.J.; Gural'skiy, I.A.; Quintero, C.M.; Tricard, S.; Salmon, L.; Molnar, G.; Bousseksou, A. Molecular actuators driven by cooperative spin-state switching. Nat. Commun. 2013, 4, 2607. [CrossRef]

35. Sy, M.; Garrot, D.; Slimani, A.; Paez-Espejo, M.; Varret, F.; Boukheddaden, K. Reversible Control by Light of the High-Spin Low-Spin Elastic Interface inside the Bistable Region of a Robust Spin-Transition Single Crystal. Angew. Chem. Int. Ed. 2016, 55, 1755-1759. [CrossRef] [PubMed]

36. Paez-Espejo, M.; Sy, M.; Boukheddaden, K. Unprecedented Bistability in Spin-Crossover Solids Based on the Retroaction of the High Spin Low-Spin Interface with the Crystal Bending. J. Am. Chem. Soc. 2018, 140, 11954-11964. [CrossRef] [PubMed]

37. Pronschinske, A.; Bruce, R.C.; Lewis, G.; Chen, Y.; Calzolari, A.; Buongiorno-nardelli, M.; Shultz, D.A.; You, W.; Dougherty, D.B. Iron(ii) spin crossover films on $\mathrm{Au}(111)$ : Scanning probe microscopy and photoelectron spectroscopy. Chem. Commun. 2013, 49, 10446-10452. [CrossRef]

38. Bi, H.; Yin, K.; Xie, X.; Zhou, Y.; Wan, S.; Banhart, F.; Sun, L. Microscopic bimetallic actuator based on a bilayer of graphene and graphene oxide. Nanoscale 2013, 5, 9123-9128. [CrossRef]

39. Bartual-Murgui, C.; Salmon, L.; Akou, A.; Thibault, C.; Molnar, G.; Mahfoud, T.; Sekkat, Z.; Real, J.A.; Bousseksou, A. High quality nano-patterned thin films of the coordination compound $\{\mathrm{Fe}$ (pyrazine) $\left.\left[\mathrm{Pt}(\mathrm{CN})_{4}\right]\right\}$ deposited layer-by-layer. New J. Chem. 2011, 35, 2089-2094. [CrossRef]

40. Cobo, S.; Molnar, G.; Carcenac, F.; Szilagyi, P.A.; Salmon, L.; Vieu, C.; Bousseksou, A. Thin films of Prussian blue: Sequential assembly, patterning and electron transport properties at the nanometric scale. J. Nanosci. Nanotechnol. 2010, 10, 5042-5050. [CrossRef]

41. Volatron, F.; Catala, L.; Rivière, E.; Gloter, A.; Stéphan, O.; Mallah, T. Spin-crossover coordination nanoparticles. Inorg. Chem. 2008, 47, 6584-6586. [CrossRef] [PubMed]

42. Moulet, L.; Daro, N.; Etrillard, C.; Létard, J.-F.; Grosjean, A.; Guionneau, P. Rational Control of Spin-Crossover Particle Sizes: From Nano- to Micro-Rods of [Fe(Htrz $\left.)_{2}(\operatorname{trz})\right]\left(\mathrm{BF}_{4}\right)$. Magnetochemistry 2016, 2, 10. [CrossRef]

43. Salmon, L.; Catala, L. Spin-crossover nanoparticles and nanocomposite materials. C. R. Chim. 2018, 21, 1230-1269. [CrossRef]

44. Pillet, S.; Hubsch, J.; Lecomte, C. Single crystal diffraction analysis of the thermal spin conversion in $\left[\mathrm{Fe}(\mathrm{btr})_{2}(\mathrm{NCS})_{2}\right]\left(\mathrm{H}_{2} \mathrm{O}\right)$ : Evidence for spin-like domain formation. Eur. Phys. J. B 2004, 38, 541-552. [CrossRef]

45. Legrand, V.; Pillet, S.; Carbonera, C.; Souhassou, M.; Letard, J.F.; Guionneau, P.; Lecomte, C. Optical, Magnetic and Structural Properties of the Spin-Crossover Complex $\left[\mathrm{Fe}(\mathrm{btr})_{2}(\mathrm{NCS})_{2}\right] \cdot \mathrm{H}_{2} \mathrm{O}$ in the Light-Induced and Thermally Quenched Metastable States. Eur. J. Inorg. Chem. 2007, 2007, 5693-5706. [CrossRef]

46. Slimani, A.; Varret, F.; Boukheddaden, K.; Chong, C.; Mishra, H.; Haasnoot, J.; Pillet, S. Visualization and quantitative analysis of spatiotemporal behavior in a first-order thermal spin transition: A stress-driven multiscale process. Phys. Rev. B 2011, 84, 094442. [CrossRef]

47. Chong, C.; Slimani, A.; Varret, F.; Boukheddaden, K.; Collet, E.; Ameline, J.C.; Bronisz, R.; Hauser, A. The kinetics features of a thermal spin transition characterized by optical microscopy on the example of [Fe(bbtr) $\left.)_{3}\right]\left(\mathrm{ClO}_{4}\right)_{2}$ single crystals: Size effect and mechanical instability. Chem. Phys. Lett. 2011, 504, $29-33$. [CrossRef]

48. Slimani, A.; Varret, F.; Boukheddaden, K.; Garrot, D.; Oubouchou, H.; Kaizaki, S. Velocity of the high-spin low-spin interface inside the thermal hysteresis loop of a spin-crossover crystal, via photothermal control of the interface motion. Phys. Rev. Lett. 2013, 110, 087208-087213. [CrossRef] [PubMed]

49. Sy, M.; Varret, F.; Boukheddaden, K.; Bouchez, G.; Marrot, J.; Kawata, S.; Kaizaki, S. Structure-driven orientation of the high-spin-low-spin interface in a spin-crossover single crystal. Angew. Chem. Int. Ed. 2014, 53, 7539-7542. [CrossRef] [PubMed]

50. Fourati, H.; Milin, E.; Slimani, A.; Chastanet, G.; Abid, Y.; Triki, S.; Boukheddaden, K. Interplay between a crystal's shape and spatiotemporal dynamics in a spin transition material. Phys. Chem. Chem. Phys. 2018, 20, 10142-10154. [CrossRef] [PubMed] 
51. Varret, F.; Slimani, A.; Boukheddaden, K.; Chong, C.; Mishra, H.; Collet, E.; Haasnoot, J.; Pillet, S. The propagation of the thermal spin transition of $\left[\mathrm{Fe}(\mathrm{btr})_{2}(\mathrm{NCS})_{2}\right][$ middle $\operatorname{dot}] \mathrm{H}_{2} \mathrm{O}$ single crystals, observed by optical microscopy. New J. Chem. 2011, 35, 2333-2340. [CrossRef]

52. Fourati, H.; Bouchez, G.; Paez-Espejo, M.; Triki, S.; Boukheddaden, K. Spatio-temporal Investigations of the Incomplete Spin Transition in a Single Crystal of $\left[\mathrm{Fe}(2-\text { pytrz })_{2}\left\{\mathrm{Pt}(\mathrm{CN})_{4}\right\}\right] \cdot 3 \mathrm{H}_{2} \mathrm{O}$ : Experiment and Theory. Crystals 2019, 9, 46. [CrossRef]

53. Sy, M.; Traiche, R.; Fourati, H.; Singh, Y.; Varret, F.; Boukheddaden, K. Spatiotemporal Investigations on Light-Driven High-Spin-Low-Spin Interface Dynamics in the Thermal Hysteresis Region of a Spin-Crossover Single Crystal. J. Phys. Chem. C 2018, 122, 20952-20962. [CrossRef]

54. Renz, F.; Spiering, H.; Goodwin, H.A.; Gütlich, P. Light-perturbed hysteresis in an iron(II) spin-crossover compound observed by the Mössbauer effect. Hyperfine Interact. 2000, 126, 155-158. [CrossRef]

55. Gütlich, P.; Hauser, A.; Spiering, H. Thermal and Optical Switching of Iron(II) Complexes. Angezwandte Chem. Int. 1994, 33, 2024-2054. [CrossRef]

56. Letard, J.F.; Guionneau, P.; Rabardel, L.; Howard, J.A.; Goeta, A.E.; Chasseau, D.; Kahn, O. Structural, Magnetic, and Photomagnetic Studies of a Mononuclear Iron(II) Derivative Exhibiting an Exceptionally Abrupt Spin Transition. Light-Induced Thermal Hysteresis Phenomenon. Inorg. Chem. 1998, 37, 4432-4441. [CrossRef]

57. Bertoni, R.; Cammarata, M.; Lorenc, M.; Matar, S.F.; Létard, J.-F.; Lemke, H.T.; Collet, E. Ultrafast Light-Induced Spin-State Trapping Photophysics Investigated in Fe(phen $)_{2}(\mathrm{NCS})_{2}$ Spin-Crossover Crystal. Acc. Chem. Res. 2015, 48, 774-781. [CrossRef] [PubMed]

58. Cannizzo, A.; Milne, C.J.; Consani, C.; Gawelda, W.; Bressler, C.; van Mourik, F.; Chergui, M. Light-induced spin crossover in Fe(II)-based complexes: The full photocycle unraveled by ultrafast optical and X-ray spectroscopies. Coord. Chem. Rev. 2010, 254, 2677-2686. [CrossRef]

59. Cook, T.; McDougall, I.; Proctor, W.; Winson, P.H. Cryogenics at Oxford Instruments. Cryogenics 1981, 21, 259-266. [CrossRef]

60. Chong, C.; Mishra, H.; Boukheddaden, K.; Denise, S.; Bouchez, G.; Collet, E.; Ameline, J.-C.; Naik, A.D.; Garcia, Y.; Varret, F. Electronic and Structural Aspects of Spin Transitions Observed by Optical Microscopy. The Case of $\left[\mathrm{Fe}(\mathrm{ptz})_{6}\right]\left(\mathrm{BF}_{4}\right)_{2}$. J. Phys. Chem. B 2010, 114, 1975-1984. [CrossRef]

61. Nakano, K.; Suemura, N.; Kawata, S.; Fuyuhiro, A.; Yagi, T.; Nasu, S.; Morimoto, S.; Kaizaki, S. Magnetic behavior and Mossbauer spectra of spin-crossover pyrazolate bridged dinuclear diiron(II) complexes: X-ray structures of high-spin and low-spin $\left[\left(\mathrm{Fe}\left(\mathrm{NCBH}_{3}\right)(\mathrm{py})\right)_{2}(\mathrm{mu}-\mathrm{bpypz})_{2}\right]$. Dalton Trans. 2004, 982-988. [CrossRef] [PubMed]

62. Létard, J.F.; Real, J.A.; Moliner, N.; Gaspar, A.B.; Capes, L.; Cador, O.; Kahn, O.J. Am. Light Induced Excited Pair Spin State in an Iron(II) Binuclear Spin-Crossover Compound. Am. Chem. Soc. 1999, 121, 10630-10631. [CrossRef]

63. Letard, J.F.; Carbonera, C.; Real, J.A.; Kawata, S.; Kaizaki, S. Photomagnetism of a series of dinuclear Iron(II) complexes. Chemistry 2009, 15, 4146-4155. [CrossRef]

64. Chastanet, G.; Carbonera, C.; Mingotaud, C.; Létard, J.F.J. Atypical photomagnetic properties in a series of binuclear iron(II) spin crossover complexes. J. Mater. Chem. 2004, 14, 3516-3523. [CrossRef]

65. Chastanet, G.; Desplanches, C.; Baldé, C.; Rosa, P.; Marchivie, M.; Guionneau, P. A critical review of the $\mathrm{T}$ (LIESST) temperature in spin crossover materials-What it is and what it is not. Chem. Squared Chem. 2018, 2, 2. [CrossRef]

66. Boukheddaden, K.; Nishino, M.; Miyashita, S. Molecular dynamics and transfer integral investigations of an elastic anharmonic model for phonon-induced spin crossover. Phys. Rev. Lett. 2008, 100, 177206-177209. [CrossRef] [PubMed]

67. Boukheddaden, K.; Miyashita, S.; Nishino, M. Elastic interaction among transition metals in one-dimensional spin-crossover solids. Phys. Rev. B 2007, 75, 094112-094122. [CrossRef]

68. Konishi, Y.; Tokoro, H.; Nishino, M.; Miyashita, S. Monte Carlo simulation of pressure-induced phase transitions in spin-crossover materials. Phys. Rev. Lett. 2008, 100, 067206-067209. [CrossRef] [PubMed]

69. Nishino, M.; Enachescu, C.; Miyashita, S.; Rikvold, P.A.; Boukheddaden, K.; Varret, F. Macroscopic nucleation phenomena in continuum media with long-range interactions. Sci. Rep. 2011, 1, 162. [CrossRef] [PubMed]

70. Enachescu, C.; Nishino, M.; Miyashita, S.; Stoleriu, L.; Stancu, A. Monte Carlo Metropolis study of cluster evolution in spin-crossover solids within the framework of a mechanoelastic model. Phys. Rev. B 2012, 86, 054114-054120. [CrossRef] 
71. Slimani, A.; Boukheddaden, K.; Varret, F.; Nishino, M.; Miyashita, S. Properties of the low-spin high-spin interface during the relaxation of spin-crossover materials, investigated through an electro-elastic model. J. Chem. Phys. 2013, 139, 194706-194713. [CrossRef]

72. Slimani, A.; Boukheddaden, K.; Varret, F.; Oubouchou, H.; Nishino, M.; Miyashita, S. Microscopic Spin-Distortion Model for Switchable Molecular Solids: Spatiotemporal Study of the Deformation Field and Local Stress at the Thermal Spin Transition. Phys. Rev. B Condens. Matter Mater. Phys. 2013, 87, 014111. [CrossRef]

73. Spiering, H.; Boukheddaden, K.; Linares, J.; Varret, F. Total Free Energy of a Spin-Crossover Molecular System. Phys. Rev. B Condens. Matter Mater. Phys. 2004, 70, 184106. [CrossRef]

74. Boukheddaden, K. Monte Carlo investigations on surface elastic energy of spin-crossover solids: Direct access to image pressure and the Eshelby constant. Phys. Rev. B 2013, 88, 134105. [CrossRef]

75. Traiche, R.; Sy, M.; Oubouchou, H.; Bouchez, G.; Varret, F.; Boukheddaden, K. Spatiotemporal Observation and Modeling of Remarkable Temperature Scan Rate Effects on the Thermal Hysteresis in a Spin-Crossover Single Crystal. J. Phys. Chem. C 2017, 121, 11700-11708. [CrossRef]

76. Gandolfi, C.; Morgan, G.G.; Albrecht, M. A magnetic iron(iii) switch with controlled and adjustable thermal response for solution processing. Dalton Trans. 2012, 41, 3726-3730. [CrossRef]

77. Brooker, S. Spin crossover with thermal hysteresis: Practicalities and lessons learnt. Chem. Soc. Rev. 2015, 44, 2880-2892. [CrossRef] [PubMed]

78. Létard, J.-F.; Chastanet, G.; Nguyen, O.; Marcén, S.; Marchivie, M.; Guionneau, P.; Chasseau, D.; Gütlich, P. Spin Crossover Properties of the $\left[\mathrm{Fe}(\mathrm{PM}-\mathrm{BiA})_{2}(\mathrm{NCS})_{2}\right]$ Complex-Phases I and II. Monatsh. Chem. Chem. Mon. 2003, 134, 165-182. [CrossRef]

79. Ichiyanagi, K.; Hebert, J.; Toupet, L.; Cailleau, H.; Guionneau, P.; Létard, J.F.; Collet, E. Nature and mechanism of the photoinduced spin transition in [Fe(PM-BiA $)_{2}(\mathrm{NCS})_{2}$ ]. Phys. Rev. B 2006, 73. [CrossRef]

80. Boukheddaden, K.; Paez-Espejo, M.; Varret, F.; Sy, M. Autocatalytic spin-crossover transition: Nonlinear dynamics induced by a photothermal instability. Phys. Rev. B 2014, 89, 224303-224311. [CrossRef]

81. Fouche, O.; Degert, J.; Jonusauskas, G.; Daro, N.; Letard, J.F.; Freysz, E. Mechanism for optical switching of the spin crossover $\left[\mathrm{Fe}\left(\mathrm{NH}_{2}-\mathrm{trz}\right)_{3}\right](\mathrm{Br})_{2} \cdot 3 \mathrm{H}_{2} \mathrm{O}$ compound at room temperature. Phys. Chem. Chem. Phys. 2010, 12, 3044-3052. [CrossRef] [PubMed]

82. Boukheddaden, K.; Shteto, I.; Hôo, B.; Varret, F. Dynamical model for spin-crossover solids. I. Relaxation effects in the mean-field approach. Phys. Rev. B 2000, 62, 14796-14805. [CrossRef]

83. Paez-Espejo, M.; Sy, M.; Varret, F.; Boukheddaden, K. Quantitative macroscopic treatment of the spatiotemporal properties of spin crossover solids based on a reaction diffusion equation. Phys. Rev. B 2014, 89, 024306-024313. [CrossRef]

84. Bousseksou, A.; Nasser, J.; Linares, J.; Boukheddaden, K.; Varret, F. Ising-like model for the two-step spin-crossover. J. Phys. I Fr. 1992, 2, 1381-1403. [CrossRef] 